\title{
Comunidade e sociedade:
}

\section{conceito e utopia}

\section{RESUMO}

Este artigo discute as noções de comunidade e sociedade, como fontes de representações simbólicas que povoam o imaginário moderno. Trata-se de um exercício de reflexão sobre conceitos entendidos não como categorias explicativas da realidade, mas como expressões de símbolos, imagens e representações que desempenham papéis importantes na dinâmica histórica. O que se pode observar, ao longo da história da modernidade, é uma tensão conceitual e simbólica das categorias de comunidade e sociedade. Assim, se por trás da imagem de sociedade estava o exorcismo da comunidade arcaica, medieval e tradicional, a força da imagem da comunidade está na sociedade, como aposta ou como ameaça.

Palavras-chave: comunidade, sociedade, modernidade.

\section{ABSTRACT}

This article discusses the notions of community and society as sources of symbolic representations that populate the modern imaginary. It is a reflection exercise about concepts understood not as explanatory categories of the reality, but as expressions of symbols, images and representations that accomplish important roles in the historic dynamic. We can observe through the history of modernity a conceptual and symbolic tension of the categories of community and society. Therefore, if behind the image of society was the exorcism of the archaic, medieval and traditional community, the strength of the community image appears in society, as a bet or as threat.

Key words: community, society, modernity.

Os conceitos comunidade e sociedade fazem parte da tradição sociológica, sobretudo weberiana. Foi Tönnies, no entanto, quem os sistematizou através dos termos $\mathrm{Ge}$ meinschaft e Gesellschaft no século XIX e, como tal, têm sido instrumentos fecundos na identificação e compreensão de contextos sociais e períodos históricos desde o século XVIII. Na verdade, enquanto instrumento de análise do real, o par comunidade-sociedade indica con- figurações sociais contrastantes, tais como o arcaico e o moderno, o afetivo e o racional, o sagrado e o secular.

O presente texto tem, contudo, um outro recorte: visa a discutir as noções de comunidade e sociedade como fontes de representações simbólicas que povoam o imaginário moderno. Trata-se de um exercício de reflexão sobre conceitos entendidos não como categorias explicativas da realidade, mas como expres- sões de símbolos, imagens e representações que, acredito, desempenham papéis importantes na dinâmica histórica. É, pois, um exercício no âmbito da Sociologia do Conhecimento.

Esse procedimento é possível quando, em tempos pós-modernos, a ciência foi destituída de sua função de teoria da verdade. Em decorrência, paradigmas, teorias, conceitos e todo o aparato científico podem ser abordados como produtos da sociedade e da história dos homens. Como Jano, tais noções têm duas faces: explicam a realidade, mas também projetam imagens dessa mesma realidade. É, pois, nesse sentido que o par comunidade e sociedade retrata imagens diferentes dos agrupamentos humanos, das interações e da história dos homens, desde o início dos tempos modernos.

A modernidade trouxe uma série de benefícios materiais e imateriais à existência humana, como a melhoria do padrão de vida em todos os seus sentidos, a idéia de liberdade individual e a possibilidade de escolha (Berger, Berger, Kellner, 1974). Tais transformações econômicas e institucionais impuseram, 
no século XVIII, a idéia de contrato social, como dominante.

O paradigma da modernidade exigia a figura racional do contrato que legitimava tudo que era bom e defensável no seio da sociedade, a qual deveria fundar-se no entrelaçamento de relações específicas, criadas pela vontade, através das quais os homens se ligariam livre e racionalmente. Durkheim (1960) chama de orgânica esse tipo de solidariedade: devido à divisão do trabalho social e técnico e à complexidade da sociedade, os indivíduos se ligam às partes que compõem o todo coletivo e participam de crenças diferentes entre si. As pessoas se relacionariam, pois, através de capacidades limitadas e não com toda sua personalidade (Nisbet, 1978). No jargão sociológico, esse tipo de contato é chamado de secundário.

Do ponto de vista individual, a modernidade impôs padrões de conduta civilizados, expressos pelo domínio do consciente sobre a emoção e a inconsciência, pelo autocontrole e pela repressão de impulsos espontâneos (Elias, 1990; Foucault, 1984). Além disso, outro aspecto importante é a idéia de progresso, já que justifica o esforço em direção a esses valores e, no limite, acarreta a obsolescência vertiginosa de produtos e criações da cultura material e imaterial. Ora, esse conjunto de características configura os indicadores empíricos da noção de sociedade; retratam, ao mesmo tempo, uma categoria explicativa e uma imagem de sociedade desejável, mas retratam também a hostilidade intelectual à comunidade tradicional, aos grupos e associações da Idade
Média, aos quais a modernidade se apresentava como antítese.

No século XIX, a noção de comunidade é resgatada e, como a sua antítese, passa a simbolizar a imagem de uma boa sociedade, pelo menos para os utópicos ou os resistentes ao modelo de solidariedade instaurado pela modernidade. $\mathrm{O}$ conceito de comunidade é empregado, nos séculos XIX e XX, para todas as formas de relacionamento caracterizadas por intimidade, profundeza emocional, engajamento moral e continuidade no tempo. Para Durkheim (1960) esse tipo de solidariedade é denominado de mecânica, já que os indivíduos se ligam ao todo sem intermediário e participam de crenças coletivas idênticas. Nesse sentido, o fundamento da comunidade está no homem visto em sua totalidade e não na multiplicidade de papéis que possa desempenhar (Nisbet, 1978). A esse tipo de contato dá-se o nome de primário, nas classificações sociológicas. Assim, a antítese da comunidade é representada pelas relações impessoais, anônimas e fracionadas, instauradas na Idade da Razão.

No Brasil, os estudos de comunidade, tão importantes para a formação da nossa Sociologia e Antropologia dos anos 40 e 50 , contribuiriam para o aprimoramento teórico e o treinamento na pesquisa científica. Cunha, Amazon Town, Xique-Xique e Marrecas, Cruz das Almas, Os parceiros do Rio Bonito, Santos e Visagens e muitos outros trabalhos foram realizados por pesquisadores estrangeiros e seus discípulos nativos; eram, ao mesmo tempo, indicadores de um objeto e definidores de uma metodologia: "estudo de um grupo local, de base territorial, integrado numa mais ampla e complexa estrutura social (...). Tais estudos implicam, pois, a transferência para o campo de investigação das sociedades mais complexas, de uma perspectiva metodológica que de há muito os antropólogos e etnológos vinham aferindo e enriquecendo no estudo das sociedades mais simples pré-letradas ou primitivas". (Nogueira, 1968, p. 171-2). $\mathrm{O}$ momento era de entusiasmo com a modernização e, se não explicitamente, pelo menos de modo subterrâneo, esse aspecto era a alavanca dos estudos de comunidade. "Do ponto de vista prático, espera-se que os estudos de comunidades (...) permitam uma eficiência maior ao trabalho de todos aqueles técnicos que, pelo caráter de suas atividades, são, ao mesmo tempo agentes de mudança social e cultural: o agrônomo, o médico, especialmente o sanitarista, o educador e outros" (Nogueira, 1968, p.177). Apostava-se na superação do Brasil arcaico e na construção de uma sociedade secular, científica, educada, moderna. Como a palavra de ordem era a mudança, esses estudos tinham o tom de registro arqueológico.

Para o bem ou para o mal, a mudança ocorreu. Como toda mudança envolve escolhas, riscos, a modernidade trouxe ganhos, mas também acarretou perdas. A expectativa de sociólogos e antropólogos de que, na modernidade, as comunidades cederiam espaço aos arranjos sociais orientados pela racionalidade, impediu-os de perceberem a importância de tradições e valores herdados da família e da comunidade, na construção da nova ordem. 
Argumenta (Hobsbawn 1997, p. 335) que formas de comportamento estranhas ao cálculo racional, como confiança mútua, motivações familiares, obediência e lealdade foram parte integrante do início do capitalismo. "O que poucos percebiam era o quanto a sociedade industrial moderna, até meados do século XX, dependia de uma simbiose da velha comunidade e de velhos valores com a nova sociedade e, portanto, como era possível que fossem dramáticos os efeitos de sua desintegração espetacularmente rápida” (Hobsbawn, 1997 , p. 333) ou seja, o desmantelamento das redes de parentesco e laços comunitários mostrou as dificuldades de se viver sem os velhos guias de comportamento que ligavam os seres humanos entre si. Desamparo, medo, violência e insegurança da vida urbana são condições emblemáticas das sociedades desenvolvidas e herança da implosão de traços culturais pré-modernos.

Talvez a conseqüência mais brutal desse processo seja o desenraizamento do mundo, isto é, a anomia. Os custos humanos da modernidade, como o fracionamento do conhecimento, o desencantamento do mundo e a perda do sentido da vida, porque colocada dentro do progresso infinito, impulsionaram a procura por outros arranjos sociais. Nessa situação de perplexidade, a imagem da comunidade emerge, inspirando utopias. Lembremos, no século XIX, Owen, Proudhon, anarquistas e, neste século, os hippies, as CEBs, os anarco-punks, as comunidades alternativas dos anos 80 e 90 , bem como solidariedades errantes que, nas palavras de (Duvignaud 1995,p. 186-7), "permitem suprir o que a vida moderna tem de abstrato e a vida cotidiana de administrativo".

Assim, se pode observar, ao longo da história da modernidade, uma tensão conceitual e simbólica das categorias comunidade e sociedade. Alguns fatos da contemporaneidade ilustram este argumento.

O pós-guerra nos mostrou a vitória do mundo dito livre e a importância da ciência nesse processo. No entanto, ele é seguido de um surto de rebeldia juvenil no mundo todo, que até hoje não se esgotou. Chamado de contracultura, era composto por grupos aparentemente heterogêneos que procuravam viver e experimentar outros padrões de comportamento. A procura de estados de consciência alterados com drogas, música ou êxtase religioso, a vida em comunidade, a preocupação ambiental, a valorização do trabalho artesanal e o resgate de traços culturais desprezados pelo ocidente e sua razão iluminista, como a cultura popular, indígena e oriental caracterizou o comportamento de hippies, psicodélicos, ecológicos e praticantes de Ioga nos anos 60 e 70. Por trás dessa revolução, estava a rejeição ao aspecto mais emblemático da sociedade: a tecnocracia, que despoja o indivíduo de competências. Lembre-se: a exigência do contrato torna tudo objeto de especialistas, tanto na esfera pública como na privada (Roszak, 1969). "Tais movimentos eram mais gritos de socorro que portadores de programas - gritos pedindo um pouco de comunidade a que pertencer num mundo anômico; um pouco de família a que pertencer num mundo de seres socialmente isolados; um pouco de refúgio na selva" (Hobsbawn, 1997, p. 335).

A exacerbação desse processo se apresenta hoje na chamada cultura alternativa. Herdeira da contracultura, porém em tempos pós-modernos, a cultura alternativa se apresenta dispersa em uma infinidade de temas: natureza, equilíbrio, respeito, reconciliação, harmonia, comunicação, intuição, pureza, comunidade, afetividade, integração, mistério, unidade, espontaneidade... São valores, condutas, atributos que povoam o simbolismo da comunidade, com os quais os alternativos se opõem ao consumismo, à competição predatória, à negligência ética e à impunidade (Soares, 1994).

Observa-se também, em muitas partes do mundo, que as políticas públicas têm procurado no conceito de comunidade, a solução para muitos dos problemas sociais da modernidade. A área da saúde é um exemplo a partir do qual o resgate da comunidade tem mostrado força. Nesse processo, são questionadas as dimensões teóricas, práticas e éticas do profissional na ordem liberal e na comunitária, que propicia uma relativização das expectativas que inspiraram a modernidade.

Nessa mesma ordem de reflexão, (Hobsbawn 1997, p. 330) lembra que, nos anos 70, os reformadores sociais, inspirados na antipsiquiatria, procuraram tirar do confinamento os doentes mentais, de modo que fossem tratados pela família ou pela comunidade. Constatou-se, todavia, que nas cidades do ocidente não há mais comunidades ou parentesco, só ruas. Eles tiveram que voltar para os hospitais... 
Já em tempos neoliberais, o movimento de dessindicalização, que se verifica desde meados dos anos 80 , abriu espaço para grupos microscópicos e errantes que fornecem abrigo para uma vida social mais viva e intensa, fora da família, da fábrica, da universidade ou do escritório. Laços de afetividade e de prazer reúnem indivíduos em torno da dança, da música, do esporte, bem como resgata cumplicidades de vizinhança e da aldeia. (Duvignaud, 1995, p. 186-7).

Esses breves exemplos sugerem o poder de força dos conceitos de comunidade e sociedade, seja na mão de planejadores sociais, seja no imaginário coletivo. Em ambos, contudo, o par conceitual desvenda os limites da ordem estabelecida e impulsiona utopias redentoras.

Do ponto de vista dos estudos acadêmicos, objetos como grupos isolados, minorias étnicas, punks, alternativos, e mesmo o interesse pelas comunidades religiosas, como as CEBs ou os Carismáticos, talvez queiram dizer alguma coisa, depois de tanto tempo de macrossociologia e estudos estruturais. Valeria a pena inventariar os estudos de comunidade mais recentes, para desvendar o que eles nos falam da sociedade. Ou, de outro modo, estaria crescendo uma microssociologia para dar conta de solidariedades inesperadas na modernidade, a qual se pretendia uniforme.

Enfim, se por trás da imagem da sociedade estava o exorcismo da comunidade arcaica, medieval e tradicional, a força da imagem da comunidade está na própria sociedade, como aposta ou como ameaça.

\section{Referências bibliográficas}

BERGER, P., BERGER, B., KELLNER, H. The homeless mind. Modernization and consciouness. New York: Vintage Books, 1974.

DURKHEIM, E. De la division $d u$ travail social. Paris: Presses Universitaires de France, 1960.

DUVIGNAUD, Jean. Solidariedade. Laços de sangue. Laços de Estado. Lisboa: Instituto Piaget, 1995.

ELIAS, N. O processo civilizador. Uma história dos costumes. Rio de Janeiro: Jorge Zahar, 1990.

FOUCAULT, M. Microfísica do poder. Rio de Janeiro, Graal, 1984.

HOBSBAWN, E. Era dos extremos. O breve século XX (1914 - 1991). São Paulo: Companhia das Letras, 1997.

NISBET, R. Comunidade. In FORACCHI, M.M., MARTINS, J.S. (orgs.). Sociologia e Sociedade. Rio de Janeiro: Livros Técnicos e Científicos, 1978.

NOGUEIRA, O. Os estudos de comunidade. In . Pesquisa social: introdução às suas técnicas. São Paulo: Editora Nacional; EDUSP, 1968, p. 171-83.

ROSZAK, T. A contracultura. Petrópolis: Vozes, 1972.

SOARES, E. S. Religioso por natureza: cultura alternativa e misticismo ecológico no Brasil. In: . O rigor da indiscipli- na. Rio de Janeiro: Relume-Dumará, 1994. 